\title{
Editorial - EFMI and active medical informatics journals in Europe
}

Biomedical informatics is a burgeoning field, with important applications and implications throughout the biomedical world and healthcare delivery. The European Journal of Biomedical Informatics (EJBI) is reacting on the great European need to share the information in the multilingual and multicultural European area.

In the year 2010 the EJBI became an official journal of the European Federation for Medical Informatics (EFMI). With these changes the journal will stress the role of information technologies and national journals supporting wide communication in many European languages.

The role of national and international medical informatics European journals is very important. In the first paper of the second issue of EJBI 2010 the role of EFMI and European medical informatics journals is described in details. The other two papers in this issue focus on robust image analysis of faces for genetic applications and on reliability of continous dichotomous measurements.

Jana Zvárová Editor-in-Chief 